\title{
UMA PERSPECTIVA DA GLOBALIZAÇÃO NA UNIVERSIDADE BRASILEIRA
}

JOSÉ VAIDERGORN ${ }^{*}$

\begin{abstract}
RESUMO: As políticas públicas relacionadas ao ensino superior brasileiro atual vêm estabelecendo seus parâmetros nos moldes da "globalização" econômica, visando sua inserção no mundo moderno, a partir de um modelo econômico "neoliberal" assumido como inevitável. As novas formas de organização do trabalho deles decorrentes impuseram um novo tipo de formação, onde o domínio do conhecimento e o tempo de escolarização passaram a ser estratégicos. Porém, a aplicação das recomendações dos órgãos internacionais no Brasil "neoliberal" privilegia a formação de nível superior fora do sistema universitário público, apontado como "atrasado" devido aos seus custos, preferindo-se uma outra, onde os critérios de "qualidade" são os empresariais. As conseqüências são evidentes, acentuando-se o atraso econômico e tecnológico, distanciando-se cada vez mais o país da modernidade.
\end{abstract}

Palavras-chave: Brasil - Universidade; Educação e desenvolvimento econômico; Política pública e educação superior; Educação superior e globalização; Ensino superior e trabalho; Ensino superior público e privado.

Examinar a Universidade brasileira e, por extensão, o ensino superior, através de uma perspectiva da globalização, traz a lembrança da metáfora da caverna de Platão na República. A sombra prismática por ela projetada permite vislumbrar parcelas dos objetos sem que se consiga observar a sua totalidade. Assim, a imaginação atua procurando desvelar o que são as obscuras formas apreendidas. Justificadas por uma compreensão peculiar dos processos identificados com a globalização, a educação superior no Brasil vem sendo questionada e pressionada a se adequar a certas demandas, oriundas dos desejos de inserção no mundo moderno, o que tem sido disseminado como inevitável.

\footnotetext{
* Professor do Departamento de Ciências da Educação e do Programa de Pós-Graduação em Educação Escolar da Faculdade de Ciências e Letras da Universidade Estadual Paulista (Unesp Campus de Araraquara).E-mail: mehrlich@correionet.com.br
} 
Em um livro clássico de investigação sociológica, Horkheimer \& Adorno (1973) tecem diversas consideraçōes sobre determinadas formas de comportamento social irrefletido. Dentre as suas instigantes e atuais observações, está a análise sobre o surgimento do preconceito, elemento fundamental dos movimentos totalitários, e sua propaganda. $\mathrm{O}$ argumento aliciador psicológico, conforme a análise da documentação coligida pelos autores, utiliza-se de um truque retórico que leva em consideração a uniformidade de um texto único, onde há constante correspondência de pensamento e repetiçóes. O pensamento preconceituoso (no caso anali-sado, o nazista) mostra-se pois como um instrumento de propaganda de rígidos estereótipos e repetições cons-tantes, tornando-se uma auto-evidência axiomática que mina as consciências críticas.

$\mathrm{O}$ movimento argumentativo inicia-se com a emissão de um juízo - que se torna um clichê - por parte de um orador que, embora apresentado como um homem comum, é também um gênio, portanto portador de uma "verdade". A simplificação do argumento, para efeito de convencimento, é acompanhada pela satisfação do ouvinte em entender a mensagem e poder repeti-la e confirmá-la. Para facilitar a compreensão, o mundo é dividido maniqueística e rigidamente, anulando-se qualquer relativismo. A auto-evidência axiomática termina portanto sendo reforçada pela repetição constante, por parte de terceiros, do argumento preconceituoso, podendo inclusive ser utilizado posteriormente pelo autor primário do raciocínio como confirmação de suas teses. Assim, mentiras passam a ter foro de verdade, criando-se a disposição para que as grandes massas acreditem e adiram a tais pontos de vista. Esta adesão é acentuada pelo ritual que cerca o exercício do poder, trans-parente e ao mesmo tempo misterioso, portador de uma razão superior à capacidade de compreensão das massas (Canetti, 1983).

Sem querer generalizar o sentido tomado pelo totalitarismo nazista, dado o exagero que sua prática tomou, e sem, é claro, dispor do paroxismo destruidor hitlerista, há algumas concepções que vêm se constituindo em auto-evidências axiomáticas do mundo contemporâneo, e que tomaram grande importância para o Brasil. São palavras-chave cuja repetição pouco criteriosa pretende obnubilar o predomínio econômico capitalista $\mathrm{e}$ as decorrências do imperialismo a ele associado (Hobsbawm, 1988 e 1995). A referência, no caso, é para a Globalização, o Neoliberalismo e, em menor escala, para a Modernidade e Modernização.

Modernidade e Modernização representam uma dupla pauta pela qual os países atrasados procuram superar esta situação, queimando etapas para alcançar os países mais adiantados (Faoro, 1992). Veblen, em um 
ensaio de 1915, teria apontado o paradoxo das vantagens do atraso dos países que sairiam das últimas filas na corrida entre as nações pelo desenvolvimento. Para ele, a modernização - aí entendida como europeização ou ocidentalização - dos países atrasados poderia ser feita às custas da assimilação e incorporação da tecnologia dos países tidos como paradigmaticamente adiantados, sem as crises sociais e econômicas por que estes passaram. Porém, ao contrário da assertiva desse autor, a modernização, assim entendida, termina adicionando às misérias herdadas do atraso as do seu próprio processo. E, lembrando Marx no Prefácio d'O Capital, uma nação pode aprender com as outras, após a descoberta de sua pista da lei natural do desenvolvimento, mas não pode saltar etapas, embora possa minorar e abreviar a fase mais dolorida.

Seguindo a pro-posição de Faoro, a dupla pauta - modernização e modernidade - contém a distinção, onde a modernidade envolve toda a sociedade, enquanto a modernização vem por um grupo co-ator, que conduz e privilegia os setores dominantes por meio de uma política economicamente orientada (ou, alternativamente, uma economia politicamente orientada). A modernidade possui uma elite estamental, que coordena e organiza o movimento, enquanto que a modernização, tal como no molde prussiano, vem do alto, separando e privilegiando a ideologia à sociedade.

O re-encanto modernizador, no caso do Brasil recente, inspirouse na concepção genericamente denominada neoliberal, legitimada nas urnas desde a restauração das eleições diretas para a Presidência, em 1989. Através do uso de "fórmulas" utilizadas inicialmente nos países do extremo Oriente (à época denominados “Tigres Asiáticos”), de economia então chamada emergente, e, posteriormente, no cumprimento das "recomendações" de instituições financeiras internacionais (Banco Mundial - Bird, Fundo Monetário Internacional - FMI, Banco Interamericano de Desenvolvimento - BID), disseminou-se que a atuação "do alto" do Estado para anular a si mesmo seria a chave da modernização. O Estado, frente à miséria, só administraria e realizaria obras públicas e assistiria a população, não fazendo distribuição de renda e nem promovendo a atividade econômica. Assim, as barreiras protecionistas vão caindo e as economias nacionais ficam cada vez mais abertas à preponderância do mercado. A educação, principalmente a básica, por outro lado, passou a ser repetidamente afirmada como o caminho mais adequado para o desenvolvimento econômico associado aos grandes avanços tecnológicos - recuperando um capítulo pouco lembrado (Os gastos do Soberano com a Educação) d'A Riqueza das Nações, de Adam Smith. 
O resultado tem sido o aprofundamento das desigualdades entre os extremos, convivendo o mundo moderno com as condições mais atrasadas. $\mathrm{O}$ progresso técnico e científico, potencialmente estendido a todos, não trouxe o bem-estar esperado. A modernização brasileira, da forma como é pretendida, não tem conseguido alcançar a modernidade. A imposição das medidas recomendadas pelos organismos internacionais na política econômica não trouxe a modernidade - e nem a trará, visto que o "neoliberalismo" anunciado no Brasil é também uma evidência auto-axiomática que não se sustenta nem nos seus rincões propugnadores. A rigor, não há nada de novo no avanço do capital e no recuo das forças que a ele resistem. A política liberal é de garantir o funcionamento do sistema econômico capitalista em todo o mundo, e o papel de instituições como o FMI, o BID e o Banco Mundial é a de resguardar a sua continuidade sem sobressaltos. Os Estados modernos, arautos do molde "neoliberal”, que nas décadas de 1970 e 1980 retoricamente apontavam o futuro no chamado "Estado mínimo" e na não intervenção do Estado na economia, contraditoriamente aumentaram no mesmo período a sua participação na economia. De acordo com um estudo da OCDE, confirmado pelo FMI, os gastos públicos do Japão e dos EUA passaram entre 1978 e 1981 de 31\% para, entre 1992 e 1995, 34\% do PIB. Nos mesmos períodos, a Alemanha passou de $48 \%$ para $49 \%$ e os demais países do G-7 (Canadá, França, Itália e Reino Unido) da média ponderada de $36 \%$ para $40 \%$. A carga tributária e o endividamento do setor público desses países, igualmente, também aumentaram, contrariando os cânones "neoliberais". Já as barreiras comerciais, enquanto vêm decrescendo (pelas pressões nos foros internacionais) nos países pobres, vêm aumentando nos ricos (Batista Jr., 1996). E, quando se anuncia a desaceleração na economia norte-americana, acompanhada das medidas controladoras (aumento dos juros bancários, diminuição do déficit comercial e das atividades industriais com a conseqüente queda no número de empregos etc.) por parte do seu governo, imediatamente entram em turbulência os mercados internacionais dela dependentes.

Da mesma forma, a idéia de globalização, eventualmente também denominada de mundialização, vem tornando-se uma evidência autoaxiomática. Seu uso comum se intensificou na década de 1990, mesmo ainda não possuindo um conteúdo perfeitamente identificável e adequado a todos os usos correntes (Ianni, 1994). No entanto, podem ser identificadas duas concepçôes distintas. A primeira delas, crítica, porém de menor impacto, identifica-a como um mito, em uma oposição aos que lhe reconhecem a inevitabilidade. Respaldando-se em dados históricos e 
estatísticos, Batista Jr (1998a, 1998b) afirma que os Estados Nacionais não estão sendo absorvidos pelos mercados mundiais, e a disseminação do contrário se presta a propósitos variados, para "vender jornais, revistas e livros superficiais (e) apanhar países ingênuos e despreparados na malha dos interesses internacionais dominantes" (1998a, p. 125).

$\mathrm{O}$ mercado nacional mantém-se fortalecido, notadamente nos países ricos e desenvolvidos. O conceito "globalização", no caso, é utilizado como uma justificação responsável por crises econômicas geradoras de desemprego e concessões ao mercado externo. As economias internacionalizam-se, mas a riqueza e a produção continuam locais e distribuídas de modo iníquo (Hirst \& Thompson, 1998).

Batista Jr. (1998b, p. 180-183) sintetiza em 5 mitos a sua crítica à globalização, chamando a atenção para, resumidamente, (1) a internacionalização econômica, que não é inédita; ao contrário, é "a reprodução, sob nova roupagem, de tendências antigas", encontradas de modo mais intenso, por exemplo, no período de 1870 a 1914; (2) o alcance e o caráter universal pretendido pelo termo globalização não provocou o desaparecimento das fronteiras ou ameaçou a sobrevivência dos Estados nacionais, embora o progresso técnico e o uso das inovações tenham contribuído para a maior integração das economias nacionais, ao mesmo tempo em que os mercados internos continuam a preponderar. A atividades econômicas continuam a se concentrar nos países desenvolvidos (dois terços ou mais dos fluxos de comércio e de capital), e os mercados de trabalho mantêm-se altamente segmentados e restritos à imigração; (3) o predomínio ideológico do neoliberalismo não diminuiu significativamente o peso do Estado na grande maioria das economias dos países desenvolvidos (tal como já indicado anteriormente); (4) a grande maioria das empresas ditas "transnacionais" não o são, permanecendo marcadamente nacionais, principalmente nas economias possuidoras de amplos mercados internos; são, pois, "firmas nacionais com operações internacionais"; e (5) a internacionalização do capital financeiro, apesar da acentuada expansão, é ainda menor que as aplicações domésticas, preponderando os mercados nacionais nos mercados de títulos e ações, ao mesmo tempo em que o volume e a velocidade das transações internacionais vêm impondo medidas de controle por parte dos bancos centrais.

A outra perspectiva no trato da globalização traduz a repetição intensa da palavra nos meios de comunicação, tornando-a habitual aos ouvidos e olhos, porém relacionada mais como adjetivo do que como substantivo, constantemente assumindo-se como uma prerrogativa vantajosa. A predominância da economia nas relaçóes mundiais e, mais ainda, 
a imposição dos interesses empresariais sobre os nacionais têm conduzido os debates sobre a globalização. Nesse sentido, muitas vezes o termo é utilizado como um artifício semântico para representar uma nova forma de imperialismo, que substitui a presença física da metrópole pelo domínio econômico internacional, garantido pelo rapidíssimo fluxo de informações que a tecnologia atual coloca à disposição. $\mathrm{O}$ imperialismo, ou antes, "o ápice do processo de internacionalização do mundo capitalista”, hoje, por ser dominação técnica e política, impondo-se no plano econômico e cultural, não mais necessita de um país-sede, apresentandose em todo o planeta (Santos, 2000).

Desde que as provocativas exposições de Hayek (1997) passaram a merecer a atenção, a idéia de uma globalização da economia passou a tomar corpo, apoiada nos avanços tecnológicos e científicos, estendendose não só para o capital, o comércio e a produção industrial como também para a cultura, as artes, os serviços, a educação etc. A pretendida superação dos Estados Nacionais por um mercado mundial, com a completa liberação das relações mercantis, seria a forma para superar a ordem arcaica e conservadora e trazer a modernidade, onde a extensão da cidadania não mais se relaciona com os direitos sociais. Nesta concepção, a transformação qualitativa e quantitativa do capitalismo, representado pela globalização, privilegia os que mantêm os bens e as riquezas, excluindo os que não as possuem. As bases nacionais do capital, embora mantidas, não mais detêm as decisões, submetidas às condiçôes do mercado mundial, generalizando um novo modo de produção, teoricamente idêntico em todo o planeta, prevalecendo a flexibilização e a terceirização associadas à automação, ao uso da microeletrônica e da informática etc. Os padrões de comportamento e os valores socioculturais, da mesma forma, são aqueles que predominam nos Estados Unidos e na Europa ocidental, e sua adesão é incentivada pela ONU e por seus organismos filiados, como a Unesco no campo educacional (Ianni, 1996).

A revolução dos transportes, decorrente das inovações técnicas, encurtou o tempo de deslocamento tanto de mercadorias quanto de informações. $\mathrm{O}$ uso de tal atributo atingiu de forma desigual os diversos setores. Na economia financeira, o fluxo contínuo de informações permite o deslocamento instantâneo de enormes volumes escriturais de capital especulativo. Já na economia produtiva, a facilidade de transporte não significou a aproximação dos extremos de riqueza e de pobreza no mundo. De fato, os ricos não mais necessitam dos pobres e de seu trabalho, aumentando conseqüentemente entre estes últimos o desemprego. A disseminação e o uso do conhecimento tecnológico na produção indus- 
trial, por sua vez, permitiram substituir com vantagens a mão-de-obra, aumentando a produtividade e diminuindo os custos.

Uma das conseqüências é a mudança do perfil do trabalhador empregado. A título de ilustração, pode-se examinar as informações contidas em uma ampla pesquisa brasileira realizada pela Fundação Seade (Sistema Estadual de Análise de Dados) e pelo Dieese (Departamento Intersindical de Estatística e Estudos Socioeconômicos) referente à área metropolitana de São Paulo. Nela, por exemplo, percebe-se uma rápida queda da participação da indústria na composição do nível de emprego na região. Em 1989, 33\% da população economicamente ativa (PEA) estava empregada na indústria; em 1996, diminuiu para $23 \%$. No mesmo período, o setor de serviços cresceu de $41,3 \%$ para $48,8 \%$ - no comércio, passou de $14,8 \%$ para $17 \% .^{1}$ Tais informações, por seu turno, devem ser contextualizadas no percentual de ocupados no município de São Paulo:

Tabela 1

\begin{tabular}{|c|c|c|c|c|c|c|c|c|c|c|c|c|}
\hline & \multicolumn{10}{|c|}{ Anos } \\
\hline & 1985 & $\begin{array}{c}1988 \\
\text { Sev a } \\
\text { dez }\end{array}$ & 1989 & 1990 & 1992 & 1993 & 1994 & 1995 & 1996 & 1997 & 1998 & 1999 \\
\hline $\begin{array}{c}\text { Populaçãa ocupacional } \\
\text { em idade ativa }\end{array}$ & 100,0 & 100,0 & 100,0 & 100,0 & 100,0 & 100,0 & 100,0 & 100,0 & 100,0 & 100,0 & 100,0 & 100,0 \\
\hline PEA & 61,3 & 62,1 & 61,9 & 60,8 & 61,9 & 61,8 & 61,3 & 61,5 & 62,4 & 62,3 & 62,4 & 62,9 \\
\hline Ocupados & 54,3 & 56,7 & 56,8 & 54,9 & 53,1 & 53,5 & 53,3 & 53,9 & 53,7 & 53,1 & 51,7 & 51,7 \\
\hline Desempregados & 7,0 & 5,5 & 5,1 & 5,9 & 8,8 & 8,3 & 8,1 & 7,6 & 8,7 & 9,2 & 10,6 & 11,2 \\
\hline Aberto & 4,4 & 4,0 & 3,8 & 4,3 & 5,4 & 4,9 & 5,1 & 5,2 & 5,8 & 5,9 & 6,9 & 7,0 \\
\hline Oculto & 2,6 & 1,5 & 1,3 & 1,6 & 3,4 & 3,4 & 2,9 & 2,5 & 3,0 & 3,3 & 3,7 & 4,2 \\
\hline Inativos & 38,7 & 37,9 & 38,1 & 39,2 & 38,1 & 38,2 & 38,7 & 38,5 & 37,6 & 37,7 & 37,6 & 37,1 \\
\hline
\end{tabular}

Fonte: SEP. Convênio Seade-Dieese. Pesquisa de Emprego e Desemprego - PED.

Associando os valores acima reproduzidos, a variação percentual da população ocupada indica, além da evidente diminuição dos postos de trabalho, que a expressiva migração para o setor terciário acentuou-se a partir de 1992 - coincidindo com a submissa assunção à "economia global", cristalizada desde os "planos econômicos" de 1990 e realçada com o Plano Real.

A globalização, como um todo, passou a ser divulgada como um novo paradigma que exigiria novos padrões para a modernidade. A indica- 
ção do rumo acertado é o da competitividade, e, dentre os seus dogmas, está o domínio da tecnologia e a habilitação do maior número de trabalhadores em maiores quantidades de conhecimentos. Como decorrência, educação passou a ser considerada como um dos pilares que possibilitam uma inserção mais vantajosa do país no mercado globalizado.

A educação superior, distintamente da básica (fornecedora da mãode-obra treinável), é estratégica, dentro dessa concepção de modernidade globalizada. Um dos fundamentos da inserção no mundo competitivo atual é o domínio e a produção do conhecimento, que passam a ser um bem - identificando-se aí um dos papéis a que se destinam as universidades. Considerando extensão da educação universitária como um indicador de competitividade, a importância que toma para os governos pode ser um índice de comparação entre países desenvolvidos, "emergentes" e em desenvolvimento, e pode mostrar também um dos motivos que a modernidade estaria mais próxima de alguns e mais distante de outros. Dados da Unesco (1994/1995) indicam que os EUA possuem 8.519.457 alunos de graduação, sendo $72,4 \%$ deles estudando em universidades públicas. A França conta com 2.150 .000 alunos, 92,2\% freqüentando escolas públicas; a Inglaterra possui 822.000 alunos, 99,9\% em escolas custeadas pelo Estado. A Argentina, com 677.000 alunos, tem 90\% deles em escolas públicas. Já o Brasil, com 1.661.034 alunos, oferece apenas $41,6 \%$ das vagas em escolas públicas $(21,9 \%$ Federais, 14\% Estaduais e 5,7\% municipais).

O quantitativo mesmo de alunos no Brasil não é tão impressionante, dada a sua população. Comparando com alguns países da América do Sul e Caribe, temos os seguintes índices: Brasil: 11,3\% da população tem título universitário; Argentina: 40\%; Bolívia: 21\%; Peru: 33\%; Uruguai: 30,1\%; Venezuela: 26,6\%; Cuba: 20,8\%; Chile: 20,6\%; Colômbia: 14,3 \%. Dos 43,6 milhōes de estudantes brasileiros em todos os níveis de ensino, somente 3,8\% (os 1.661 .034 acima citados) fazem faculdade (MEC - Ministério da Educação e do Desporto, Brasil; e Brunner, 1994).

O sistema universitário brasileiro, iniciado apenas em 1934 com a criação da USP (primeira universidade organizada em torno da tríade ensino, pesquisa e extensão, conforme o modelo europeu - notadamente o francês e, em menor escala, o alemão), expandiu-se em uma rede onde convivem universidades públicas e particulares com escolas superiores isoladas. A evolução do crescimento das matrículas é a seguinte: 1960: 95.691 (sendo 42.067 - 44\% - na rede particular); 1970: 425.478 (214.865 - 50\% - na rede particular); 1980: 1.377 .286 (885.054 - 
64\% - na rede particular); 1990: 1.540 .080 (961.455 - 63\% - na rede particular); e 1994: 1.661 .034 ( 970.584 - 58\% - na rede particular). $\mathrm{O}$ crescimento da oferta de vagas na rede particular de ensino, indo no contra-fluxo dos países acima citados (dentre eles os mais desenvolvidos do planeta), é explicado por diversos motivos. Desde a Reforma Universitária de 1968 (Lei n ${ }^{\circ}$ 5.540/1968), o Governo federal facilitou muito a criação de cursos superiores isolados particulares, como uma forma de suprir a demanda de vagas que as escolas públicas não davam conta. A desobrigação do Estado em incrementar o ensino superior na época permitiu a constituição de um forte setor de faculdades particulares, verdadeiras e poderosas empresas que, ao se constituírem em universidades, passaram a disputar as verbas públicas com as instituições do Estado, mesmo apresentando uma qualidade muito aquém. Por outro lado, sempre houve o interesse dos grupos religiosos, principalmente católicos, em aumentar sua influência na sociedade civil. Em termos qualitativos, as universidades públicas brasileiras possuem, de acordo com os mais recentes dados do MEC (1995), uma formação nitidamente melhor de seu quadro docente que as particulares:

Tabela 2

\begin{tabular}{|c|c|c|c|c|}
\hline & Graduação & Especialização* & Mestrado & Doutorado \\
\hline Federal & $22 \%$ & $23 \%$ & $34 \%$ & $21 \%$ \\
\hline Estadual** $^{*}$ & $24 \%$ & $25 \%$ & $22 \%$ & $29 \%$ \\
\hline Municipal & $19 \%$ & $62 \%$ & $15 \%$ & $4 \%$ \\
\hline Particular & $29 \%$ & $45 \%$ & $19 \%$ & $7 \%$ \\
\hline
\end{tabular}

*Curso de Pós-Graduação lato senso, de no mínimo 360 horas de atividades.

** Inclui as universidades de todos os estados brasileiros.

Mesmo considerando o baixo percentual de estudantes universitários brasileiros, é apreciável o seu número. Porém, dentro dos parâmetros comparativos de produtividade, as 52 universidades ou instituições federais, com orçamento total de mais de $\mathrm{R} \$ 5$ bilhões (aproximadamente US\$ 4,7 bilhões) para o ano de 1996, o que significa cerca de 3,8\% do PIB $^{2}$ (incluídas aí as universidades estaduais do estado de São Paulo - USP, Unesp e Unicamp, as mais importantes do País em termos de produção acadêmica, e que recebem um percentual de pouco mais de $9 \%$ da arrecadação do Imposto de Circulação de Mercadorias e 
de Serviços do Estado como as principais - e quase únicas - verbas orçamentárias) têm um resultado social inferior, por exemplo, ao da Coréia, que destina percentual semelhante de seu PNB para inversão no ensino superior.

A percepção de tal circunstância por parte das elites brasileiras levou a procura de medidas que pudessem colocar o país nos trilhos da modernidade. Após oito anos de marchas e contramarchas, promulgouse a nova Lei de Diretrizes e Bases da Educação (LDB) em 17 de dezembro de 1996. Em termos de ensino superior, algumas novidades passaram a ser possíveis, para responder mesmo àquelas demandas que seriam próprias da inserção do Brasil no mundo globalizado. $\mathrm{O}$ modelo-padrão para universidades brasileiras passou a ser questionado, dado o intento de definição do caráter e vocação de cada uma (ensino de graduação, pesquisa de ponta, vinculação regional etc). Circula também com desenvoltura a proposta do economista do BID, Cláudio de Moura e Castro, que agrega ao modelo atual de universidade (com ensino, pesquisa e extensão) a possibilidade de escolas superiores de formação profissional de alto nível, outras de formação superior técnica, e outras de formação geral, todas possibilitadas pela nova LDB. Um dos resultados é a proliferação de "Institutos Superiores de Educação", escolas que passaram a formar rapidamente licenciados em nível superior, cuja qualidade e conseqüências para o ensino básico ainda não foram aquilatadas.

A lógica que rege tais medidas é própria da nova direita modernizadora, uma concepção de política que vem de outros tempos e que se apossou do Estado brasileiro. Mesmo revestida de um discurso adequado às exigências das instituiçôes de fomento econômico mundial, pretende substituir todas as demais concepçóes que de alguma forma visam atingir uma "justiça social", fundamentada na extensão da cidadania.

No campo educacional, esta nova direita propõe, de acordo com Whitty (1984), um cardápio de sugestōes que diariamente podem ser observadas, sendo cotidianamente incorporadas ou propostas como novidades:

- Privatização dos serviços custeados por verbas públicas através do pagamento pelos usuários;

- privatização dos serviços antes feitos por pessoal próprio (terceirizaçăo);

- venda de bens ou empresas ou seu uso para reversão em ganhos monetários (prédios, editoras, laboratórios, hospitais etc.) através de fundações, que aproveitam o espaço público. 
Inversamente, as verbas públicas, para esta concepção, passam a auxiliar a atividade privada por meio de subsídios a pessoas ou instituições educativas, desviando-se fundos públicos de pesquisa para universidades privadas, que passam a ocupar os lugares estratégicos de decisão. A mesma proposição da nova direita dispóe-se a diminuir as verbas para a educação pública e desviá-las para as escolas privadas, de acordo com as políticas de reforma acadêmica, que têm como corolário a diminuição de custos por estudante.

Tais políticas, aplicadas indiscriminadamente no caso brasileiro, geraram proposiçôes duvidosas mesmo com o uso de argumentos aparentemente progressistas, como a opção feita pelo governo federal pela educação básica como prioritária por 10 anos, ou a experiência de extensão de conceitos industriais de "qualidade total" na educação (incluindo-se, por exemplo, formas arbitrárias de avaliação e de concessão de verbas).

A política no ensino superior parte de alguns argumentos cuja aplicação resulta sofística. Por exemplo, em 1996, cerca de 67\% dos estudantes das universidades públicas eram oriundos das escolas particulares de $1^{\circ}$ e $2^{\circ}$ graus. Isto está, na verdade, de acordo com o quadro social, onde os $20 \%$ da população mais rica detêm $62,6 \%$ da renda (dados de 1995, IBGE). Nesse mesmo ano, dos 43,6 milhões de estudantes brasileiros, em todos os níveis de ensino, só 3,8\% faziam faculdades (confira na Tabela 2 a distribuição desse total entre as redes públicas e particulares).

Os professores universitários, por sua vez, têm sido tentados a moldar seus interesses profissionais aos acenos dessa concepção empresarial de educação, privatizante e financeiramente compensadora se comparada com os dispêndios estatais, mostrando que o ensino superior, quando gerido como negócio lucrativo, parece ser bem compensador. Dado este quadro, as conseqüências que se avizinham já podem ser perfeitamente imaginadas. Dentre elas, a diminuição das verbas para a educação superior pública e o seu desvio para as escolas privadas, em nome de uma duvidosa necessidade de qualificação das últimas (atestada, por exemplo, pelos exames nacionais dos alunos formandos em cada curso), terminam criando uma falsa competição, já que os fins de cada uma são diferentes.

A ânsia pela modernidade globalizada no Brasil promove a convivência do atraso com os grandes avanços científicos, na pauta estabelecida pelas elites. A pretendida reforma do Estado, destinada a torná-lo mais eficiente e "moderno", de acordo com os cânones "neoliberais", e adequados à "globalização", passou a vislumbrar um modelo 
derivado do setor privado, cujo padrão relaciona-se à concepção gerencial de "qualidade". Algumas medidas ensaiadas - como a exigência de prestação de contas de todas as instituições de ensino superior, que deverão destinar no mínimo $60 \%$ das suas receitas para o pagamento de professores - ao lado de cortes de verbas, principalmente das universidades federais, e outras medidas administrativas vêm apontando para uma tendência de "privatização" do ensino superior.

Ao apontar a Universidade pública brasileira não como parte da solução para os problemas do atraso, mas como obstáculo para a modernidade globalizada, sob argumentos que afastam as discussōes de fundo, do sentido mesmo do ensino superior no Brasil, e que se concentram nos aspectos administrativos e não-científicos, as elites criam uma nova auto-evidência axiomática destinada a congregar, em torno dos argumentos fáceis, uma visão de Estado perfeitamente adequada às pretensōes de um mundo onde os papéis principais já estão destinados, e onde dificilmente o Brasil irá aparecer.

Se nada for feito para estancar esse movimento, a Universidade, deixando de ser o "santuário do saber", tal como aponta Wolf (1993), terminará perdendo a identificação de seu papel social, levando consigo a liberdade acadêmica, que se limitará às opiniōes politicamente aceitáveis nos círculos do poder, aproximando-se perigosamente de um autoritarismo disfarçado mesmo de consenso.

\section{Notas}

1. Para efeito de comparação, o Seade apresenta uma tabela da distribuição da população ocupada, por setor de atividade econômica, no estado de São Paulo, no Brasil e em países selecionados (África do Sul, Alemanha, Austrália, Bolívia, Canadá, Chile, China, Colômbia, Coréia do Sul, Espanha, EUA, França, Holanda, Hong-Kong, Índia, Itália, Japão, México, Paraguai, Peru, Portugal, Reino Unido, Suécia, Uruguai e Venezuela), no período entre 1980 e 1993. Cf. http://www.seade.gov.br/ titabpv98/?sg=TBL

2. Os dados, expostos na revista Conjuntura Econômica (editada pela Fundação Getúlio Vargas), possuem uma certa astúcia na exposição. Os gastos esgrimidos pelo Ministro da Educação atingem 4,5\% do PIB em 1996, porém nesse total estão inclusos todos os níveis escolares de todas as esferas de Executivo (municipal, estadual e federal), somados às aposentadorias e pensões e à merenda escolar (que tem sua verba debitada da conta da Previdência). A aplicação mesmo no ensino em 1996 é equivalente ao do ano de 1991.

\section{A PERSPECTIVE OF GLOBALIZATION IN BRAZILIAN UNIVERSITIES}

ABSTRACT: Based on a "neoliberal" economical model assumed as unavoidable and aimed at inserting Brazil in the modern world, the public policies related to the present Brazilian higher education have established 
their parameters along the lines of the economical "globalization". The new forms of labor organization that followed have imposed new types of tuition, in which mastery of knowledge and schooling time have turned out strategic. Unfortunately, in a "neoliberal" Brazil, applying the international agencies" recommendations means privileging higher level training outside the public university system, considered as "backward" owing to its costs. Preference is thus given to tuition adopting entrepreneurial "quality" criteria, whose consequences are obvious: the economical and technological backwardness becomes more pronounced and the country keeps farther and farther from modernity.

Key words: Brasil - University; Education and Economical Development; Public Policies and Higher Education; Higher Education and Globalization; Higher Education and Work; Public and Private Higher Education.

\section{Referências bibliográficas}

BATISTA Jr., P.N. "Neoliberalismo": revolta contra o século 20. Opinião Econômica. Folha de S. Paulo, 5 dez. 1996, p. 2-2.

Mitos da "globalização". Estudos Avançados, São Paulo, jan./ abril 1998, 32(12), p. 125-186.

BRUNNER, J.J. Educación Superior en America Latina. 1994 (mimeo).

CANETTI, E. Massa e poder. Trad. de Rodolfo Krestan, Brasília/São Paulo: Editora da UnB/Melhoramentos, 1983.

FAORO, R. A questão nacional: A modernização. Estudos Avançados, São Paulo, jan./abril 1992, 6(14), p. 7-22.

HAYEK, F.V. O caminho da servidão. Rio de Janeiro: Globo, 1997.

HIRST, P. \& THOMPSON, G. Globalização em questão: Economia internacional e as possibilidades de governabilidade. Petrópolis: Vozes, 1998.

HOBSBAWM, E.J. Era dos extremos: O breve século XX - 1914-1991. $2^{a}$ ed. Trad. de Marcos Santarrita, São Paulo: Companhia das Letras, 1995.

A era dos Impérios. Trad. de S.M. Campos e Y.S. de Toledo. Rio de Janeiro: Paz \& Terra, 1988. 
HORKHEIMER, M. \& ADORNO, T.W. Temas básicos de Sociologia. Trad. de Álvaro Cabral, São Paulo:Cultrix/Edusp, 1973.

IANNI, O. Globalização: Novo paradigma das Ciências Sociais. Estudos Avançados, São Paulo, maio/ago. 1994, 8(21), p. 147-163.

Teorias da globalização. $2^{\mathrm{a}}$ ed. Rio de Janeiro: Civilização Brasileira, 1996.

SANTOS, Milton. Por uma outra globalização. Do pensamento único à consciência universal. $3^{\mathrm{a}}$ ed. Rio de Janeiro: Record, 2000.

UNESCO. Anuário estatístico, 1995.

WHITTY, G. "Aproximaciones cambiantes a la politica educacional: El legado de la socialdemocracia y la respuesta del tacherismo". In:

Enguita, M.F. (Org.), Marxismo y Sociologia de la Educación,

Barcelona: Laia, 1984.

WOLF, R.P. O Ideal de Universidade. São Paulo: Editora da Unesp, 1993. 